\title{
Stability and Change in Managerial Work Values: A Longitudinal Study of China, Hong Kong, and the U.S.
}

\author{
David A. Ralston, ${ }^{1}$ James Pounder, ${ }^{2}$ Garlos W. H. Lo, ${ }^{3}$ \\ Yim-Yu Wong, ${ }^{4}$ Carolyn P. Egri, ${ }^{5}$ and Joseph Stauffer ${ }^{6}$ \\ ${ }^{1}$ University of Oklahoma, USA, ${ }^{2}$ Higher Colleges of Technology, United Arab Emirates, ${ }^{3}$ Hong \\ Kong Polytechnic University, Hong Kong (SAR), ${ }^{4}$ San Francisco State University, USA, ${ }^{5}$ Simon \\ Fraser University, Canada, ${ }^{6}$ Texas A $\mathcal{E}^{2} M$, USA
}

\begin{abstract}
This study presents a 12-year (1989-2001) longitudinal comparison of managerial values systems in China, Hong Kong, and the U.S. Using hierarchical cluster analysis, we test the validity of the three competing perspectives -

convergence, divergence, and crossvergence - on values system evolution in these three societies. We use the sociocultural influence and business ideology influence typology as the foundation for developing our hypotheses. Additionally, we assess the contribution of the specific values within the values system to the overall system values findings. Our data most strongly support the multicultural crossvergence perspective. During a time period of stability in the U.S. and substantial change in both Hong Kong and China, the values of Hong Kong and China became more similar, while the values of these two Greater China societies became more different from those of the U.S.
\end{abstract}

\section{INTRODUGTION}

Do changes in societal values require years, decades, or centuries? This question has been debated for decades (Webber, 1969). The debate focuses around the convergence, divergence, or crossvergence perspectives, as well as the reasons or influences that lead to each of these three perspectives (Dunphy, 1987; Ralston, Holt, Terpstra, and Yu, 1997). The purpose of the current study is to shed some additional insight on this debate using longitudinal data from three societies.

Ralston, Gustafson, Cheung, and Terpstra (1993) observed differences in values among mainland China, Hong Kong, and the U.S. in 1989. The goal of this crosssectional study was to assess the level of values convergence-divergence-crossvergence among these societies. Hong Kong was the focus of the Ralston et al. (1993) 
study because of the intermixed influences that the Chinese culture and British rule have had on Hong Kong over the past century. However, this study had one substantial limitation: cross-sectional investigations are not able to provide definitive conclusions regarding the nature and processes of values change (Inglehart, 1997; Inglehart and Baker, 2000; Ralston et al., 1997; Tan, 2002). Building on the Ralston et al. (1993) study, the purpose of the current study was to assess longitudinal changes that might have occurred across these three societies during a period of substantial change in both China and Hong Kong while relative stability prevailed in the U.S. during the same time period. If there is short-term change (convergence) in global values, we would expect there to be greater similarity of values across these three societies in our 2001 study than there were in the Ralston et al. (1993) study. Thus, our data, in conjunction with the data of the Ralston et al. (1993) study, allow us to examine longitudinal values evolution that is not possible in a cross-sectional analysis.

Since 1989, a variety of changes in the global business environment has taken place. In the U.S., change has been the most subtle. For example, Inglehart (1997) found there has been a relatively minor shift in intergenerational values in the U.S. Conversely, changes in mainland China and Hong Kong over this period have been much more dramatic. According to Inglehart, these changes appear to be linked to the dynamic nature of the economic and political shifts that have occurred in mainland China and Hong Kong. Furthermore, the Internet has evolved into a major source of information and communication, and satellites have begun to broadcast global television into formerly closed mainland China (Hong, 1998). The Chinese economy has taken major steps in its transition to a market economy, resulting in gaining WTO membership in 2001 (Chen, 2002). One of the most significant political changes that occurred between 1989 and 2001 was the reunification of Hong Kong with mainland China, which resulted in the onecountry, two-system plan, with Hong Kong being a Special Administrative Region (SAR) of the People's Republic of China (Holliday and Wong, 2003).

Because of these changes, ranging from the subtle to the dramatic, these three locations provide a very interesting context for a longitudinal comparison. Thus, our primary research question is: What has been the impact of the sociocultural and business ideology influences on the managerial work values in these three societies? To answer this question, we considered the alternative predictions of the convergence, divergence, and crossvergence perspectives on change in societal values systems (Dunphy, 1987; Ralston et al., 1997; Webber, 1969). We also investigated changes in the specific values used to constitute a values system, because understanding why changes in specific values took place - or did not - should provide greater insight into how and why values systems evolve. We identified eight values that are meaningful and relevant for assessing managerial work values. This approach allows us to assess the level of stability and change in values systems across these three societies over this 12-year period (between 1989 and 2001). This 
approach also allows us to assess which values are most (and least) susceptible to change, as well as to examine the patterns of changes in these values.

We begin our discussion of these issues by reviewing the literature on the convergence, divergence, and crossvergence perspectives of values change. Following that, we discuss two types of influences on managerial work value systems, namely sociocultural influence and business ideology influence. We discuss which of the eight specific values are most likely to be influenced by sociocultural or business ideology forces. The result is two subsystems of values. Next, we integrate our discussions of the three values change perspectives with the two types of influences on managerial work values in order to develop three competing hypotheses. We test these hypotheses at the values system level and at the values subsystem level, as determined by the influence typology. To provide greater in-depth understanding of the reasons underlying the values evolution, we conduct an analysis for each of the eight specific values. We conclude the article with a discussion of our findings that, in part, challenge current theory. Lastly, we discuss the theoretical and practical implications of these findings.

\section{CONCEPTUAL BACKGROUND AND HYPOTHESES}

\section{Three Perspectives on Values Change}

The convergence, divergence, and crossvergence perspectives on change offer three alternative predictions regarding the cross-cultural development of managerial values (Dunphy, 1987; Ralston et al., 1997). The convergence-divergence debate in the international business arena goes back at least four decades (Webber, 1969), while the crossvergence concept emerged in this debate about a decade ago (Ralston et al., 1993). An important aspect of the convergence divergence debate focuses on the time needed for change to occur, as we shall discuss.

Convergence. Convergence theorists argue that industrialization and technology are the primary driving forces for the global merging of work values. These same theorists believe that such historic shifts reflect in significant ways the development of Western capitalism as it is influenced primarily by technology (Dunphy, 1987). Their point should be well taken, especially across well-established, stable societies. However, in the context of developing and transitioning economies, one could question whether technology is a sufficient explanation. In these developing and/or transitioning societies, we see that changes in economic (e.g., mainland China) and political (e.g., Russia) systems appear to be having substantial impact on the work values of these societies (Yip, 1992) and that these systems can change more rapidly, relative to the change in the sociocultural system of a society.

Furthermore, technology tends to flourish in capitalistic systems where entrepreneurs and venture capitalists can exploit new ideas quickly (Suarez-Villa, 2000). Capitalistic systems, while not creating democracies, tend to result in a lessening 
of political constraints so that market economies can function (Peng and Shekshnia, 2001). In turn, maturing economic systems tend to invest more in technological development (Suarez-Villa, 2000). Recent research shows that highly developed societies with political democracies and high levels of technological sophistication tend to cluster together, and all correlate positively with the level of economic development (Keefer and Knack, 1997). Therefore, given this interrelatedness of technological, political, and economic development, these three forces form an integrated set of stimuli. We refer to this as the 'business ideology' paradigm. The synergistic effect of these three aspects of the business ideology paradigm serves as the force for values convergence across societies. For example, as capitalism flourishes, communism declines; and levels of technological sophistication become more universal.

Divergence. In contrast, proponents of the divergence perspective argue that the values system of a society is deeply embedded in its cultural roots. Divergence theorists, thus, posit a values system as the product of sociocultural influences (Inkeles, 1997). From this perspective, national culture differences reflect enduring cultural heritages that are deeply embedded in individuals (Ricks, Toyne, and Martinez, 1990). The divergence approach argues that the values and beliefs learned during childhood socialization endure throughout one's lifetime irrespective of business ideology changes in the society, and that these values are passed from one generation to the next generation. As such, values change because sociocultural influence is a very slow process that should be measured in terms of generations and centuries (Inglehart and Baker, 2000; Ralston, Egri, Stewart, Terpstra, and Yu, 1999).

Crossvergence. Crossvergence is a more recently developed concept. Ralston et al. (1997) define crossvergence as the synergistic interaction of sociocultural and economic ideology influences within a society that result in a unique value system. This perspective sees that values system as different from the values supported solely by either sociocultural or economic ideology influences. In this definition, economic ideology reflects the economic system that individuals within a society experience, with technology being an implicit part of it. However, in today's multifaceted global environment, it appears that the Ralston et al. (1997) definition may be too narrow. Consequently, we propose to expand the economic ideology concept to that of the business ideology paradigm. This approach incorporates the political and technological influences as well as the economic influences upon the values system of a society. Thus, we expand the definition of crossvergence to propose that the business ideology forces leading to convergence and the sociocultural forces leading to divergence will synergistically interact with one another. The result is a unique values system that differs from both the convergence and divergence positions. 
Looking at crossvergence at the values system level, one or more of the eight values that constitute the values system for this study could change; yet others could remain unchanged. The result of the integration of certain values that have remained constant and other values that have changed would be a newly evolved and unique values system. To more fully understand the overall change in a values system, it is important to ascertain which specific, subsystem-level values are changing and the directions in which they are changing. This expanded level of analysis would seem particularly relevant to understanding the evolution of developing and/or transitioning societies where we find business ideology subjected to greater and more rapid change than in stable, well-developed societies. Thus, the convergence-divergence-crossvergence $(\mathrm{C}-\mathrm{D}-\mathrm{C})$ debate focuses on two key points of disagreement that are inextricably intertwined. One debate concerns the primary influence on values systems formation: Is business ideology or sociocultural impact the primary influence? A second debate regards the time lapse: Do values systems change over the span of years or over the span of centuries?

In summary, the convergence perspective argues that the primary influence is business ideology and that change can occur within years. The divergence perspective argues that the primary influence is the sociocultural impact and that change evolves slowly over centuries (Webber, 1969). The crossvergence perspective attempts to bridge this divide by accepting that the sociocultural and business ideology explanations are both viable, and that they are inherently interactive (Ralston et al., 1997). This approach further acknowledges that some aspects of a values system may change over a period of years while other aspects of a values system may take generations or centuries to change. This view argues that for a fuller appreciation of the dynamics of values change, one must simultaneously consider the longitudinal aspects of sociocultural and business ideology influences. Thus, from the crossvergence perspective, the essential question is: To what degree and at what speed do various aspects of a society's values system change? By comparing three societies that have experienced different degrees of change and sources of change, we sought to contribute to the resolution of the convergence-divergence-crossvergence debate.

\section{Two Types of Influence that Shape Values Systems}

While a cultural group has one values system, we identify two potentially competing sets of influences - business ideology and sociocultural - which shape that values system. Additionally, the malleability of the specific values identifies the potential impact that these two sets of influences might have on the overall values system. Convergence would argue that all values are malleable and thus susceptible to the influence of business ideology; divergence would argue that all values are enduring vestiges of a society's sociocultural heritage. The crossvergence perspective argues that some values are malleable to the influence of business ideol- 
ogy, while other values are rigidly enduring and more sociocultural influenced. As such, this issue might be oversimplified as a contrast between the needs of the business world versus ingrained personal philosophy. However, given that all values originate from individual cultural and philosophical upbringing, then all values may be shaped to some extent by one's experience in the business world. Thus, the question that now arises is: Which values tend to be fundamental and unchanging tenets of one's philosophical upbringing, and which values tend to be more susceptible to the pressures of one's work environment?

The works of Rokeach (1973) and Schwartz (1992) identify a contrast between terminal and instrumental values that is theoretically consistent with the crossvergence perspective. Socioculturally ingrained values are deeply rooted in the core social fabric of the society. Therefore, these values are less likely to change in response to business ideology influences (i.e., economic, political, and technological changes). Values that are more peripheral, on the other hand, are more susceptible to change when there are economic, political and/or technological changes. Thus, change to any of these aspects of business ideology influence can have a substantial impact upon these instrumental values.

Based upon the existing literature, Ralston et al. (1993) developed a values system that consists of eight specific values. Collectively, these eight values constitute a model of the managerial work values in terms of managers' views and valuation of the superior-subordinate relationship (integration), managers' orientation toward employee welfare versus task accomplishment (human-heartedness), managers' approach to influencing others at work (Machiavellianism), and managers' feelings of control over their work environment (locus of control). Furthermore, these values dimensions incorporate the importance of trust in relationships (Confucian work dynamism), the emphasis on one's self-interest versus the good of others (moral discipline), one's orientation toward wanting security and avoiding risks (intolerance of ambiguity), and the acceptance of new ideas and change (dogmatism). Within the context of these eight values, we further refine our research question: Which of these eight values are core values that are influenced primarily by sociocultural factors, and which are peripheral values that are influenced primarily by business ideology factors?

Sociocultural influenced values. The values of Confucian dynamism, moral discipline, intolerance of ambiguity, and dogmatism are not in the exclusive domain of sociocultural control. Yet these tenets are more culturally imbued than determined by business ideology because they appear to be, to a significant degree, fundamental to a society's values and less so to the influences of the business world.

Confucianism is a philosophy which, in addition to professing the importance of developing a long-term orientation, identifies a hierarchical structure in which family is central. The Confucian perspective of work dynamism is based on an individual's level of search for virtue (Chinese Culture Connection, 1987). Confucian 
work dynamism was adopted as the 'fifth' Hofstede (2001) dimension, and has been described as a measure of long-term orientation. Implicit in this values system is the importance of developing a trust-based relationship with business associates. Both Fukuyama (1995) and Inglehart (1997) have shown that a high level of societal trust appears to be related to the economic development level of a country.

Moral discipline describes a long-held belief about relationships with family and friends. It is positively related to the cultural value of 'collectivism' and identifies an individual's level of self-control in relation to others, particularly regarding whether individuals see themselves as an integral part of a collective or not. The research of Ralston et al. (1997), Schwartz (1992), and Triandis (1995) concurs that collectivism can be a primary factor in differentiating cultural groups.

Intolerance of ambiguity relates to the inability to cope with major environmental change and conflict (Timothy, Thoresen, Pucik, and Welbourne, 1999). Numerous studies have demonstrated the relevance of intolerance of ambiguity for understanding differences across cultures and use the term as a proxy for conservatism (e.g., Dollinger, 1983; Martin and Westie, 1959). A low score on intolerance of ambiguity identifies societal members' ability to function with a feeling of relative certainty even when confronted by a dynamic and changing environment, such as the changing political environment of Hong Kong or the changing economic environment of China.

Dogmatism is related to personality rigidity. It is a pervading adherence to the traditional voice of authority and a reluctance to challenge the status quo. It indicates the degree of flexibility or openness to new ideas and change (Davies, 1998; Schulze, 1962). Schwartz (1992) identified the importance of this value in his 20 -country study in developing a cross-culturally validated measure of values. Schwartz's study includes the values dimension of openness-to-change versus conservation (dogmatism). The value constructs of Schwartz have proved important in understanding values orientations among different age groups of Chinese and Americans (Egri and Ralston, 2004).

Business ideology influenced values. Integration, human-heartedness, Machiavellianism, and locus of control clearly appear to be work-related and influenced by work environments.

Integration is an indicator of the formal power relationship that is acceptable between a superior and a subordinate. Integration is negatively related to power distance (Hofstede, 2001), which identifies the degree of hierarchical distance between a superior and a subordinate that is considered as acceptable. High integration would mean low preference for hierarchical structures, formal rules, and authoritative leadership. Thus, integration may serve as an indicator of the degree of centralization that is regarded as appropriate within a work organization.

Human-heartedness describes the management style of an individual as either people-oriented or task-oriented. Thus, the human-heartedness value relates to the 
typology of an individual's leadership style (Bass, 1990). It may also be viewed as comparable to the masculinity-femininity culture value (Hofstede, 2001) with human-heartedness positively associated with a 'feminine' approach (peopleoriented) rather than a 'masculine' (task-oriented) management style. Additionally, this value identifies an individual's level of social consciousness and compassion toward others.

Machiavellianism taps into the individual's strategy for gaining influence. This tactic identifies a manager's willingness to use social power and to place selfinterest above the interest of the work group (Jaffe, Nebenzahl, and Gotesdyner, 1989). Recognition of the importance of the ability to influence others by various informal means goes back centuries. In the West, Machiavelli (1513/1984) was one of the early writers, while Chinese General Sun's (1963) influential discourse, The Art of War, predates Machiavelli by a century. More recently, Kotter (1985) was among the first to identify the importance of understanding the concepts of power (as informal influences) in the business world. At the same time, Kipnis, Schmidt, and Wilkinson's (1980) seminal work on influence tactics laid the modern business foundation for the importance of understanding the work implications of influence tactics, such as Machiavellianism. Interestingly, those scoring high on Machiavellianism, while tending to be good administrators, also qualify as sociopaths who tend to possess low ideological commitment, with more concern for a personal agenda (Nelson and Gilbertson, 1991).

Locus of control relates to managers' attitude regarding the extent to which they have control over events and, therefore, over their ability to bring about change (Blau, 1987; Rotter, 1966; Spector, 1982). High internal locus of control managers tend to act on their belief that they have control over outcomes at work. High external locus of control managers are more likely to passively attribute work outcomes to factors such as influential others (e.g., government) or chance. Research has found that people with an internal locus of control are more self-motivated (Judge and Bono, 2001), are more proactive in terms of striving for achievement (Spector, 1982), and have the predisposition to be more effective leaders (Blau, 1993). Trompenaars (1996) reported that, in general, managers in North America have a higher internal locus of control than do managers in the Far East.

\section{Hypotheses}

The overarching goal of this study is to explore whether there is longitudinal evidence of a global convergence of values (in sole support of the business ideology perspective), a societal divergence of values (in sole support of the sociocultural perspective), or a multicultural crossvergence of values (in support of the crossvergence perspective, an integrative impact of the sociocultural and business ideology forces). As has been noted, previous discussions and tests of the convergence-divergence-crossvergence $\mathrm{C}-\mathrm{D}-\mathrm{C}$ debate have been at the cross- 
sectional level of analysis. For the longitudinal study of the $\mathrm{C}-\mathrm{D}-\mathrm{C}$ issue for multiple societies, we argue that it is important to conceptualize the values change in terms of the whole values system to provide a holistic investigation of the C-D-C issue. We present three competing hypotheses to represent each of these values change perspectives. While these hypotheses are presented at the values system level, we will also assess these same hypotheses at the subsystems business ideology and sociocultural level.

Convergence hypothesis. The convergence perspective would predict that any differences in values in 1989 would disappear or significantly decline by the 2001 time period such that the values systems of the three societies would be more similar in 2001 than in 1989. Based on the technology-driven orientation of classical convergence thinking (Webber, 1969), this would also mean that the convergence would be in the direction of the U.S. values system, which in 1989 was the most technologically sophisticated of these three societies.

Hypothesis 1: Based on the convergence perspective (business ideology influence), there will be a significant decrease in the differences across the values systems of the three societies from time period one (1989) to time period two (2001).

Divergence hypothesis. In contrast, the divergence perspective would predict cultural stability across this 12-year time period; any cross-cultural differences in values systems found in 1989 would remain in 2001. Thus, there would be consistency in the uniqueness of each society's values system regardless of the degree of intersocietal contact or changes in the business ideology of the societies during this period.

Hypothesis 2: Based on the divergence perspective (sociocultural influence), there will be continued differences in the values systems of the three societies from time period one (1989) to time period two (2001).

Crossvergence hypothesis. The crossvergence perspective is more complex. In essence, it would predict an interaction between business ideology and sociocultural influences that would result in a cross-cultural evolution of values systems between 1989 and 2001. That is, specific values may change in independent ways such that values systems may evolve in a multitude of plausible ways. Since crossvergence theory proposes that there will be an interaction of business ideology and sociocultural influences to create a new values system, we developed two interrelated crossvergence hypotheses based upon convergence predictions for the business ideology values and divergence predictions for the sociocultural values. Crossvergence theory would predict that the 2001 managerial work values systems in each society would be substantively different from those observed in 1989, with specific values 
changing to different degrees and in different directions to produce different across-society relationships in 2001 . We use Hong Kong as the focal society, as did Ralston et al. (1993), to predict a converging of business ideology values for Hong Kong with the U.S., and a continued divergence of socioculturally influenced values for Hong Kong and the U.S. We predict less difference between Hong Kong and mainland China for business ideology values over time, and continuing differences between Hong Kong and mainland China for sociocultural values.

Hypothesis 3a: Based on the crossvergence perspective (interaction of business ideology and socio-cultural influences), Hong Kong will be more similar to the U.S. in 2001 than it was in 1989 on the values primarily impacted by business ideology infuences (integration, humanheartedness, Machiavellianism, and locus of control).

Hypothesis 3b: Based on the crossvergence perspective, Hong Kong will continue to be different from either mainland China or the U.S. in 2001 as it was in 1989 on the values primarily impacted by sociocultural infuences (Confucian dynamism, moral discipline, intolerance of ambiguity, and dogmatism).

To summarize, if there is a significant decrease in the differences across the values of the three societies from 1989 to 2001, then values system convergence has occurred. Conversely, if there continues to be differences in the values of the three societies over this time period, then values system divergence has occurred. Lastly, if there are changes in the interrelationships of one or more of the specific values among the three societies over this time period, then values system crossvergence has occurred. In addition, knowledge of values evolution on specific values, as well as the values system as a whole, contributes to a more in-depth interpretation of the findings. Thus, we conduct analysis on the specific values to better identify the degree of change in specific aspects of a society's values system.

\section{METHOD}

\section{Sample and Procedure}

The 1989 U.S. sample of managers came from corporations located in northeastern business centers of the U.S.; and a territory-wide data collection was conducted for Hong Kong. The 1989 data used Shanghai as the mainland China data collection site. As the traditional center of commerce in mainland China, Shanghai has been identified as reflecting the most cosmopolitan business values of the Mainland (Ralston, Yu, Wang, Terpstra, and He, 1996). It should be noted that a Shanghai sample may not be representative of managers in all other regions of mainland China (Ralston et al., 1996). The Chinese government considers Shanghai as its 'capital' of social-market economics and the epitome of what Chinese business 
throughout the country should aspire to. While Shanghai business may not be representative of average business behaviour in mainland China, its government endorsement as the model of Chinese business is significant in terms of present and future country-wide comparisons. There are also cultural and contextual similarities between Shanghai and Hong Kong in that Shanghai's economic development has emulated pre-reunification Hong Kong (Liao and Sohmen, 2001). Similarly, there may be regional differences within the U.S. that may influence our conclusions regarding cross-cultural differences in managerial work values systems. However, comparable to Shanghai in mainland China, the Northeast U.S. includes New York City and Boston, which are prominent centers for U.S. business. Thus, this study was designed to compare the business centers of these three locations. In 2001, we collected data from the same locations as those in 1989.

We relied on a mail survey for our Hong Kong data collections. Individuals who were full-time employees and part-time graduate students had the task of asking managers/professionals from their companies to participate, anonymously, in this survey. In 1989, the students identified two participants each. In 2001, they identified four participants. We employed a comparable approach in the U.S. The response rates for Hong Kong and the U.S. exceeded 70\%. Data collections in mainland China were conducted prior to training classes with respondent anonymity provided (response rates exceeded $80 \%$ in both years). The number of participants per company was comparable to those in Hong Kong and in the U.S. Concerns regarding the limited quality of the mail service in mainland China in 1989 negated the use of a mail survey at that time. To maintain consistency, we used the same survey approach in 2001.

The 1989 sample consisted of 326 managers total (mainland China, $n=82$; Hong Kong, $n=182$; and the U.S., $n=62$ ). The 2001 sample consisted of 770 managers in mainland China, 156 in Hong Kong-SAR, and 151 in the U.S. Given that statistical tests (e.g., $t$-tests) are more robust to violations of the homogeneity of variance assumption when sample sizes are more similar (see Glass and Hopkins, 1970), we used the SPSS random-selection procedure to obtain a more comparable sample size for the China 2001 sample. Thus, the 2001 sample for this study consisted of 450 managers total (mainland China, $n=150$; Hong KongSAR, $n=150$; and the U.S., $n=150$ ). Table 1 presents the demographic data for Chinese, Hong Kong, and U.S. respondents in each time period.

\section{Measures}

We selected measures that had been established as valid, reliable, and sensitive to socially desirable response biases (Adler, Campbell, and Laurent, 1989). Mainland China and Hong Kong are two societies in which responding to questionnaires could raise concern for the respondent's well-being or job security, especially in the late-1980s. Furthermore, since measures validated in one culture have been criti- 
Table 1. Participant demographics for the three locations and the two data collection years

\begin{tabular}{|c|c|c|c|c|c|c|}
\hline \multirow[t]{2}{*}{ Demographics } & \multicolumn{2}{|l|}{ U.S. } & \multicolumn{2}{|l|}{ Hong Kong } & \multicolumn{2}{|l|}{ China } \\
\hline & $\begin{array}{l}1989 \\
(n=62)\end{array}$ & $\begin{array}{l}2001 \\
(n=150)\end{array}$ & $\begin{array}{l}1989 \\
(n=182)\end{array}$ & $\begin{array}{l}2001 \\
(n=150)\end{array}$ & $\begin{array}{l}1989 \\
(n=82)\end{array}$ & $\begin{array}{l}2001 \\
(n=150)\end{array}$ \\
\hline $\begin{array}{l}\text { Age } \\
\text { (mean years) }\end{array}$ & 37 & 34 & 35 & 32 & 39 & 36 \\
\hline Gender ( $\%$ male $)$ & 54 & 57 & 79 & 60 & 92 & 80 \\
\hline $\begin{array}{l}\text { Education } \\
\text { (mean years) }\end{array}$ & 15.0 & 16.4 & 13.7 & 13.1 & 14.5 & 14.8 \\
\hline $\begin{array}{l}\text { Managerial experience } \\
\text { (mean years) }\end{array}$ & 6.9 & 4.6 & 6.0 & 5.3 & 5.7 & 7.1 \\
\hline $\begin{array}{l}\text { Number of employers } \\
\text { (mean) }\end{array}$ & 3.0 & 3.3 & 3.2 & 3.0 & 2.5 & 2.5 \\
\hline
\end{tabular}

cized for their lack of cross-cultural generalizability (Adler et al., 1989), we included measures developed in both Eastern (Chinese) and Western cultures. As a result, we used four Eastern-developed (Chinese) and four Western-developed measures in assessing the values of the managers in each society. At the beginning of the questionnaire, respondents were informed that there was no right or wrong answer, only their opinions mattered; therefore, they should simply express how they felt.

Eastern-developed measures of values. The Eastern-developed values that we selected are: integration, human-heartedness, Confucian work dynamism, and moral discipline. These values are the four dimensions of the Chinese Value Survey (CVS), which is a validated instrument derived from Chinese societal values (Chinese Culture Connection, 1987). The integration dimension is an 11-item scale; the human-heartedness dimension is a 5 -item scale; the Confucian work dynamism dimension is an 8-item scale; and the moral discipline dimension is a 5-item scale. All four CVS dimensions can have scores that range from 1 to 9, with a higher score indicating a stronger belief in a value. We used the Chinese and English language versions that had been created by the Chinese Culture Connection (1987).

Western-developed measures of values. While the four values of Machiavellianism, locus of control, intolerance of ambiguity, and dogmatism were developed in a Western culture, they appear to have face validity and relevance for assessing values in both economically developed and developing societies (e.g., Jost, Glaser, Kruglanski, and Sulloway, 2003; Spector, Sanchez, Siu, Salgado, and Ma, 2004; Tan, 2002). The measures were translated into Chinese and back-translated until there was agreement between the translators. Machiavellianism was measured using Christie's (1968) 20-item Mach IV instrument, with higher scores indicating a preference for 
the use of social power (score range: 40 to 160). Locus of control was measured with Rotter's (1966) 23-item internal-external control instrument. Scores can range from 0 to 23, with higher scores indicating a strong tendency to feel externally controlled. Intolerance of ambiguity was measured using Martin and Westie's (1959) 8-item scale. Scores can range from 5 to 40 , with higher scores indicating a desire for more certainty. Dogmatism was measured using Schulze's (1962) 10-item Short Dogmatism scale on which higher scores indicate a more rigid personality (score range: 10 to 70 ).

When taken together, these eight values were designed to profile the fundamental nature of a values system that determines managerial behaviour. The ranges of scale reliabilities (Cronbach's $\alpha$ ) for the 2001 samples were: mainland China (0.61-0.77), Hong Kong (0.62-0.80), and U.S. $(0.60-0.75) .{ }^{[1]}$ These scale reliabilities are comparable to those obtained by Tan (2002), who used the same scales in his study of managerial values systems of ethnic Chinese in the U.S., Singapore, and mainland China (total sample $\alpha=0.62$ to 0.92 ).

\section{Analysis}

We used two types of statistical analyses: first, hierarchical cluster analysis is used both at the societal system level and at the business ideology and sociocultural subsystem levels; and second, analysis of variance was performed for each specific value.

Values system and subsystem analyses. The objectives of the hierarchical cluster analyses were twofold. First, we investigated values convergence, divergence, or crossvergence across the two time periods and the three societies for the eight values simultaneously to determine the values systems similarity or difference. To check whether sample differences in demographic characteristics contributed to the cluster analysis results, we conducted a comparable cluster analysis that included the demographic characteristics of age, gender, and education level. Given differences in measurement scales, the cultural values and demographic variables were standardized to a mean of zero and a standard deviation of one so that all variables were on the same metric in determining cluster distances (Aldenderfer and Blashfield, 1984). Second, we split the specific values into two groups according to those proposed to be more business ideology influenced (integration, human-heartedness, Machiavellianism, and locus of control) and those proposed to be more socioculturally oriented (Confucian work dynamism, moral discipline, intolerance of ambiguity, and dogmatism). We then performed hierarchical cluster analyses for each of these groups to determine if similar or different patterns resulted when these unique sets of influence were isolated.

Consistent with other international business studies (e.g., Merchant, 2000), we used Ward's hierarchical cluster procedure, which is a statistically robust proce- 
dure that maximizes within-cluster homogeneity and between-cluster heterogeneity (Aldenderfer and Blashfield, 1984). Prior to conducting the hierarchical cluster analyses, we calculated the inter-rater agreement $\left(\mathbf{r}_{\mathrm{WG}}\right)$ for each values dimension according to the methods prescribed by James, Demaree, and Wolf (1993). The $r_{W G}$ statistics for the eight society/time period groups are presented in the Appendix. On average, the $r_{W G}$ was 0.94 for integration, 0.92 for human-heartedness, 0.86 for Machiavellianism, 0.68 for locus of control, 0.94 for Confucian dynamism, 0.88 for moral discipline, 0.80 for intolerance of ambiguity, and 0.80 for dogmatism. Overall, there was a high level of inter-rater agreement with only four of the $48 \mathrm{r}_{\mathrm{WG}}$ statistics $(0.66,0.64,0.64$, and 0.67 - all on the integration dimension) being below the recommended cut-off level of 0.70 .

The determination of the number of clusters for each analysis was based on examination of increases in the agglomeration coefficient, where large increases indicate the merging of dissimilar clusters. The number of clusters was determined by visual inspection of a dendogram, a graph which shows the degree of similarity of joined observations along a rescaled distance cluster combine scale (using Ward's algorithm). On this scale, low scores $($ minimum $=0$ ) for the linkage between groups indicate high within-cluster group similarity, whereas high scores $($ maximum $=25)$ indicate high within-cluster group dissimilarity.

Specific value level analysis. Our first objective was to identify the values system patterns of these societies; the objective of the second set of analyses was to test statistically within-time period differences and within-society changes across time periods for the specific values. For these analyses, we used t-tests to identify changes in values within each society from time period one (1989) to time period two (2001), then ANOVA F-test with Bonferroni multiple comparison t-tests to identify change across these three societies within each of the two time periods.

\section{RESULTS}

Values system convergence would be indicated if the cluster analysis showed that the 1989 societal groups were in dissimilar clusters, but the 2001 societal groups formed a homogeneous cluster. Support for values system divergence would be indicated if the cluster analysis results showed that each set (1989 and 2001) of within-society groups formed dissimilar (heterogeneous) clusters. Values systems crossvergence would be indicated if the clustering for the 2001 societal groups was significantly different from the clustering for the 1989 societal groups.

\section{Values Evolution at the Overall System Level}

As Figure 1 shows (la: Overall value systems), the cluster analysis dendogram for the eight cultural values revealed three major clusters in the data. The first cluster 
1a. Overall value systems

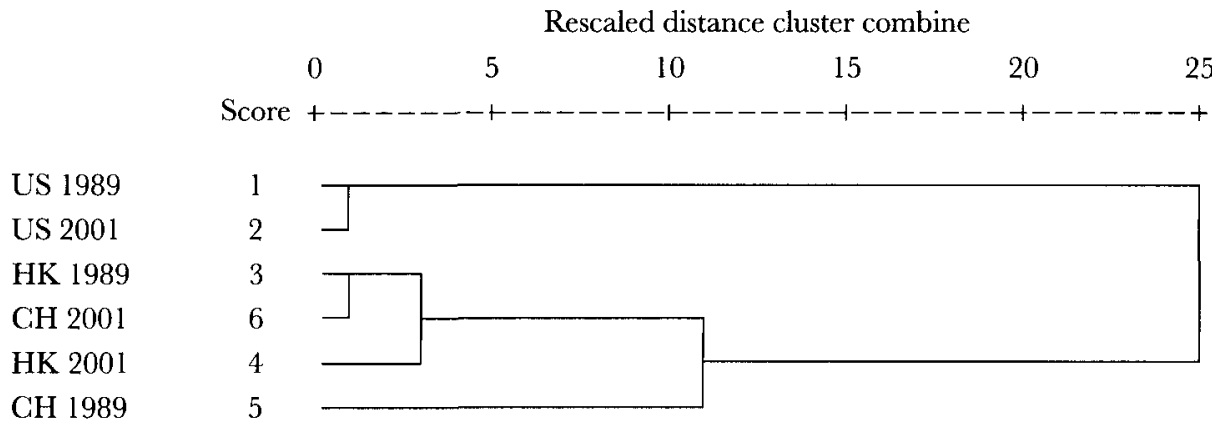

Ib. Overall value systems controlling for demographic characteristics of age, gender, and education
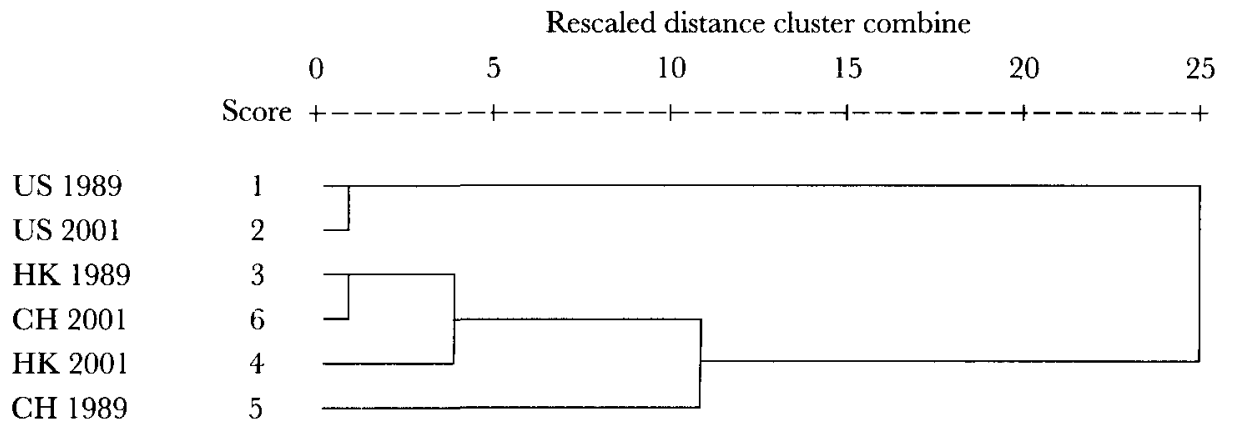

Figure 1. Dendograms obtained from hierarchical cluster analysis using Ward's method

consists of the U.S. 1989 and U.S. 2001 groups. The second cluster consists of the Hong Kong 1989, mainland China 2001, and Hong Kong 2001 groups; the third cluster consists of the mainland China 1989 group. The cluster analysis for the eight cultural values and demographic characteristics variables yielded the same three-cluster solution (see Figure 1b: Overall value systems controlling for demographic characteristics of age, gender, and education), thereby indicating that the primary determinants of group similarities and/or dissimilarities were cultural values systems, not demographic characteristics.

The cluster analysis results suggest both cultural divergence and convergence. There has been cultural value system stability for the U.S. with the large cluster distance between the U.S. cluster and the Greater China (mainland China and Hong Kong) groups. For Hong Kong, there has been minimal change in cultural values systems. For mainland China, there has been significant change in cultural values systems, with mainland China 1989 being a separate cluster and mainland China 2001 being in the same cluster as Hong Kong 1989 and Hong Kong 2001. These results suggest that there has been a regional convergence of mainland 
2a. Business ideology values: Integration, human-heartedness, Machiavellianism, and locus of control

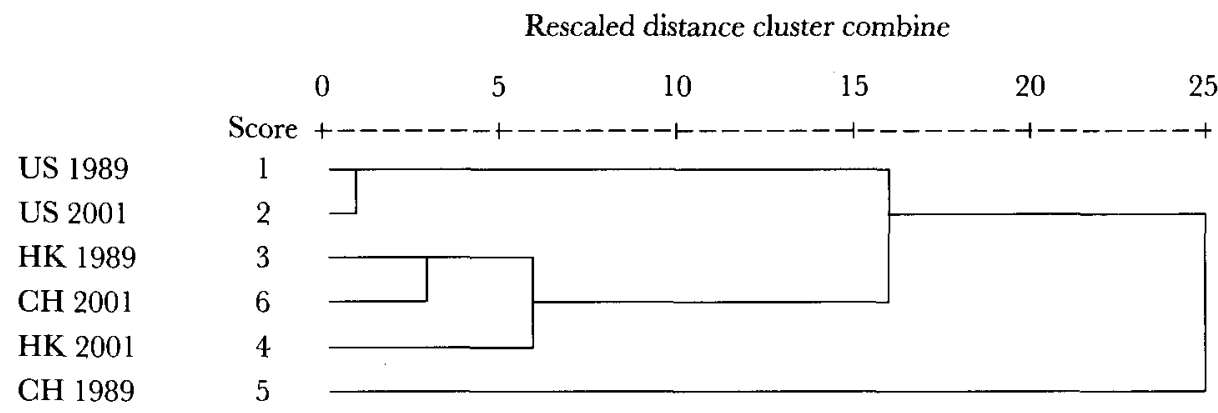

2b. Socio-cultural values: Confucian work dynamism, moral discipline, intolerance of ambiguity, and dogmatism

Rescaled distance cluster combine

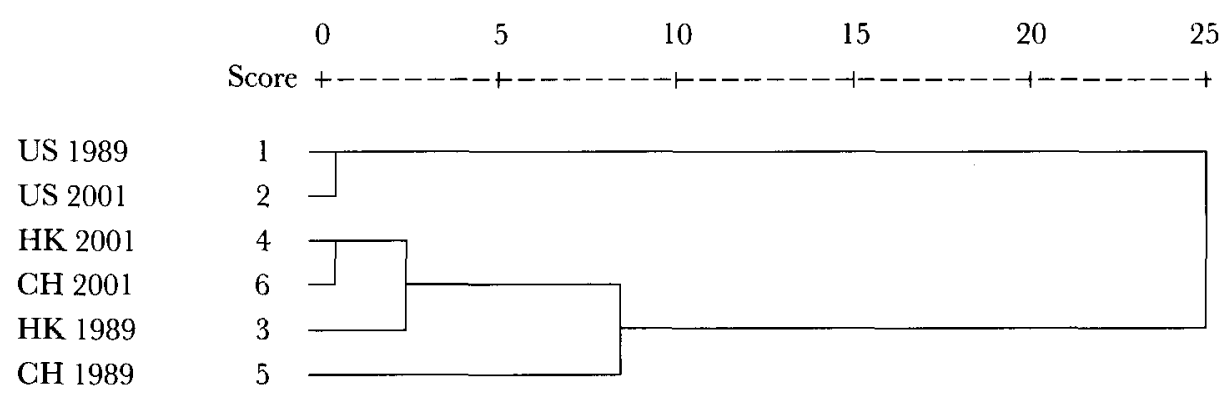

Figure 2. Dendograms obtained from hierarchical cluster analysis using Ward's method

China's cultural values system towards those of Hong Kong over the 1989 to 2001 period, while there has been continuing global divergence between the U.S. and Greater China.

\section{Evolution in the Business Ideology and Sociocultural Values}

Business ideology values. As Figure 2 shows (2a. Business ideology values), the four business ideology values (integration, human-heartedness, Machiavellianism, and locus of control) collectively reveal a pattern that is the same as the pattern found at the overall values system level in Figure 1. The U.S. continues on its divergent path, as does Hong Kong, showing no change in clusters between 1989 and 2001. However, as at the system level, mainland China shows the greatest change as mainland China 1989 moves from being a cluster unto itself in 1989 to being part of the Hong Kong (1989 and 2001) cluster in 2001. Longitudinally, there was no change for the U.S., no change for Hong Kong; yet there was change for main- 
Table 2. Means and standard deviations of the eight values for each society with t-test comparisons of societal change across the 1989-2001 time period ${ }^{\mathrm{a}}$

\begin{tabular}{|c|c|c|c|c|c|c|c|c|c|}
\hline \multirow[t]{2}{*}{ Values } & \multicolumn{3}{|l|}{ U.S. } & \multicolumn{3}{|c|}{ Hong Kong } & \multicolumn{3}{|l|}{ China } \\
\hline & 1989 & 2001 & $t$ & 1989 & 2001 & $t$ & 1989 & 2001 & $t$ \\
\hline \multicolumn{10}{|l|}{ Business ideology } \\
\hline Integration & $\begin{array}{l}5.7 \\
(0.43)\end{array}$ & $\begin{array}{c}5.7 \\
(0.54)\end{array}$ & 0.00 & $\begin{array}{l}5.6 \\
(0.59)\end{array}$ & $\begin{array}{l}5.7 \\
(0.53)\end{array}$ & 1.61 & $\begin{array}{l}5.1 \\
(0.65)\end{array}$ & $\begin{array}{l}5.6 \\
(0.56)\end{array}$ & $6.51 *$ \\
\hline Human-heartedness & $\begin{array}{l}5.9 \\
(0.78)\end{array}$ & $\begin{array}{c}5.9 \\
(0.89)\end{array}$ & 0.00 & $\begin{array}{c}5.5 \\
(0.73)\end{array}$ & $\begin{array}{c}5.9 \\
(0.58)\end{array}$ & $5.18^{*}$ & $\begin{array}{l}4.9 \\
(0.53)\end{array}$ & $\begin{array}{c}5.3 \\
(0.59)\end{array}$ & $4.17 *$ \\
\hline Machiavellianism & $\begin{array}{l}83.9 \\
(10.60)\end{array}$ & $\begin{array}{l}83.6 \\
(10.82)\end{array}$ & 0.15 & $\begin{array}{l}89.5 \\
(15.80)\end{array}$ & $\begin{array}{l}94.9 \\
(11.33)\end{array}$ & $3.62^{*}$ & $\begin{array}{l}86.1 \\
(17.43)\end{array}$ & $\begin{array}{l}93.2 \\
(12.91)\end{array}$ & $3.86^{*}$ \\
\hline Locus of control & $\begin{array}{l}8.1 \\
(4.01)\end{array}$ & $\begin{array}{l}8.0 \\
(3.69)\end{array}$ & 0.17 & $\begin{array}{l}10.8 \\
(4.15)\end{array}$ & $\begin{array}{l}12.5 \\
(4.14)\end{array}$ & $3.91^{*}$ & $\begin{array}{l}12.3 \\
(3.95)\end{array}$ & $\begin{array}{l}11.9 \\
(3.44)\end{array}$ & 0.75 \\
\hline \multicolumn{10}{|l|}{ Sociocultural } \\
\hline $\begin{array}{l}\text { Confucian work } \\
\text { dynamism }\end{array}$ & $\begin{array}{l}4.9 \\
(0.58)\end{array}$ & $\begin{array}{l}4.7 \\
(0.59)\end{array}$ & 2.32 & $\begin{array}{l}5.1 \\
(0.56)\end{array}$ & $\begin{array}{l}5.4 \\
(0.51)\end{array}$ & $4.76^{*}$ & $\begin{array}{c}5.3 \\
(0.57)\end{array}$ & $\begin{array}{l}5.2 \\
(0.62)\end{array}$ & 1.27 \\
\hline Moral discipline & $\begin{array}{l}4.0 \\
(0.80)\end{array}$ & $\begin{array}{l}3.9 \\
(0.71)\end{array}$ & 0.77 & $\begin{array}{l}4.2 \\
(0.88)\end{array}$ & $\begin{array}{l}4.3 \\
\langle 0.81)\end{array}$ & 0.77 & $\begin{array}{l}3.9 \\
(0.96)\end{array}$ & $\begin{array}{c}4.3 \\
\langle 0.96\rangle\end{array}$ & $3.42^{*}$ \\
\hline $\begin{array}{c}\text { Intolerance of } \\
\text { ambiguity }\end{array}$ & $\begin{array}{l}19.8 \\
(4.59)\end{array}$ & $\begin{array}{l}19.9 \\
(4.07)\end{array}$ & 0.15 & $\begin{array}{l}22.1 \\
(4.68)\end{array}$ & $\begin{array}{l}23.8 \\
(3.58)\end{array}$ & $3.53^{*}$ & $\begin{array}{l}24.7 \\
(4.78)\end{array}$ & $\begin{array}{l}23.8 \\
(4.30)\end{array}$ & 1.52 \\
\hline Dogmatism & $\begin{array}{l}34.7 \\
(8.41)\end{array}$ & $\begin{array}{l}34.1 \\
(7.20)\end{array}$ & 0.52 & $\begin{array}{l}43.6 \\
(7.74)\end{array}$ & $\begin{array}{l}42.0 \\
(7.33)\end{array}$ & 1.90 & $\begin{array}{l}42.1 \\
(5.37)\end{array}$ & $\begin{array}{l}42.4 \\
(8.80)\end{array}$ & 0.29 \\
\hline
\end{tabular}

Notes: ${ }^{a}$ Standard deviations are presented in parentheses under each mean score; ${ }^{*} p<0.05$.

land China. Thus, it appears that mainland China's transition to a capitalistic economic system has had an impact on these business ideology values.

For the four specific values of the business ideology influence, the t-tests acrosstime within each society (see Table 2), and the F-tests and Bonferroni multiple comparison tests across societies (see Table 3) provide further insights into how business ideology is influencing change within Greater China. We found that the change of integration values in mainland China appears to be the primary driving force for the values shift in mainland China toward Hong Kong, as well as toward the U.S. Over the period of this study, the Chinese perspective of the appropriate 'power distance' between superior and subordinate has significantly decreased such that mainland China has converged with Hong Kong and the U.S. in 2001, to the extent that there is no significant difference among the three societies. For human-heartedness, there has been a comparable increase in people-orientation in both Hong Kong and mainland China over this 12-year period, such that they remain divergent from one another. However, this movement has resulted in Greater China being more similar to the U.S. on this value, with the nonsignificant difference between Hong Kong and U.S. indicating a cross-cultural convergence. For locus of control, we found that both Hong Kong and mainland 
Table 3. The across-society ANOVA F-test within each time period for the eight values with Bonferroni t-test multiple comparison test of country differences

\begin{tabular}{llll}
\hline \hline Individual values & Date & $F$ & Country differences \\
\hline Business ideology influence & & & \\
$\quad$ Integration & 1989 & $23.16^{* * *}$ & (U.S., HK) $>$ China \\
& 2001 & 2.23 & U.S. $=$ HK $=$ China \\
Human-heartedness & 1989 & $20.81^{* * *}$ & U.S. $>$ HK $>$ China \\
Machiavellianism & 2001 & $22.78^{* * *}$ & (U.S., HK) $>$ China \\
& 1989 & $7.40^{* * *}$ & (HK, China) $>$ U.S. \\
Locus of control & 2001 & $45.05^{* * *}$ & (HK, China) $>$ U.S. \\
Sociocultural influence & 1989 & $30.28^{* * *}$ & China $>$ HK $>$ U.S. \\
Confucian work dynamism & 2001 & $58.44^{* * *}$ & (China, HK) $>$ U.S. \\
Moral discipline & 1989 & $3.49^{*}$ & China $>$ HK $>$ U.S. \\
& 2001 & $30.23^{* * *}$ & (HK, China) $>$ U.S. \\
Intolerance of ambiguity & 1989 & 1.30 & HK $=$ U.S. $=$ China \\
& 2001 & $6.22^{* *}$ & (HK, China) $>$ U.S. \\
Dogmatism & 1989 & $39.69^{* * *}$ & China $>$ HK $>$ U.S. \\
& 2001 & $42.81^{* * *}$ & (HK, China) $>$ U.S. \\
& 1989 & $30.98^{* * *}$ & (HK, China) $>$ U.S. \\
\hline \hline
\end{tabular}

Notes: ${ }^{*} \mathrm{p}<0.05,{ }^{* *} \mathrm{p}<0.01,{ }^{* * *} \mathrm{p}<0.001$.

China changed, with Hong Kong's change being significantly in the direction of mainland China, such that the significant difference between these societies in 1989 did not exist in 2001, thereby indicating regional convergence. Conversely, the divergent difference between Greater China and the U.S. remained. The results for Machiavellianism are similar to those for human-heartedness in that there was a significant increase in this value for both Hong Kong and mainland China over the time period, but this increase was in parallel, such that their divergent relationship remained intact. However, the increase in Machiavellianism for Greater China is in a direction away from, rather than towards, the U.S., as was the case for human-heartedness. This result suggests an interesting anomaly for the convergence and divergence perspectives that do not account for this type of values change.

Sociocultural values. Figure 2 shows (2b. Sociocultural values) a somewhat different pattern for the four values influenced most strongly by sociocultural influences (Confucian work dynamism, moral discipline, intolerance of ambiguity, and dogmatism). As in the previous analyses, we found divergence in the socialcultural influenced values for each of the three societies in 1989. However, as the second level of linkages in Figure 2 shows, the sociocultural influenced values changed in 2001 with mainland China and Hong Kong being in the same cluster and the U.S. remaining 
divergent. This finding implies that there has been a mutual merging of values rather than a shift of values in mainland China towards Hong Kong, contrary to what the business ideology values reflected. In essence, this finding may indicate that for Hong Kong people an individual-level outcome from the influence of political reunification is their pragmatic rediscovering of their Chinese roots.

As Table 3 shows, all four values in the sociocultural cluster were identical between 1989 and 2001, with Hong Kong and mainland China being significantly different from the U.S., while these two Greater Ghina societies were not significantly different from one another. This phenomenon might be described as regional (cultural) convergence with continuing global divergence. Nonetheless, of these four dimensions, only dogmatism had the same set of relationships in 1989 . Therefore, only dogmatism had true across-time values divergence. For Confucian work dynamism and intolerance of ambiguity in 1989, mainland China was significantly higher than Hong Kong, which in turn was significantly higher than the U.S. Thus, we found divergence among all three societies in 1989. Table 2 shows that in both these cases there was a merging of values across time, with Hong Kong scores increasing significantly and mainland China scores decreasing to the point where there were no significant differences in 2001 for Confucian work dynamism and intolerance of ambiguity between the two locations. However, moral discipline is the most interesting finding among the sociocultural influences and appears to be a driving force among these influences. In 1989, there was no significant difference among these three societies on this dimension. Although Hong Kong's score increased (non-significantly), the significant increase for mainland China over this time period resulted in identical mean scores and therefore non-significant differences within Greater China in 2001. What makes this finding even more interesting is that there was global convergence in 1989 and global divergence in 2001. Neither convergence nor divergence theory address this type of change, just as they were not designed to address the Machiavellianism change reported previously within the business ideology group.

\section{DISCUSSION}

The 1989 to 2001 time period was one of economic and political stability in the U.S. (Inglehart and Baker, 2000), economic evolution in mainland China (Liao and Sohmen, 2001), and political change in Hong Kong (Shir and Choy, 2005). Our findings not only seem consistent with the events of this period, they also illustrate the impact of such events on societal values. In that regard, we now return to our primary research question: What has been the impact of business ideology and sociocultural influences on the managerial work values systems in these three societies? We begin our discussion of this question by summarizing our values systemlevel findings in the context of our convergence, divergence, and crossvergence hypotheses. 


\section{Findings on Values Systems in Support of Crossvergence}

At the system level, we found a cultural crossvergence across these three societies. We likewise found crossvergence effects for both the business ideology and the sociocultural influenced subsets of values. At the specific values level, we found a combination of longitudinal convergence, divergence, and crossvergence results, which is consistent with the definition of values crossvergence at the systems level. Thus, this study clearly found a crossvergence of values. This crossvergence at the values system level might best be described as global divergence with regional (cultural) convergence. This finding is consistent with Axelrod's (1997) model, which proposed that similar cultures in proximity tend to interact and in turn become more similar with one another, while dissimilar cultures, whether in proximity or not, tend to remain dissimilar from one another.

In 1989, Hong Kong was significantly different from both the U.S. and mainland China. In 2001, Hong Kong and the U.S. maintained their cultural divergence, while Hong Kong and mainland China converged. Given the political repatriation of Hong Kong with mainland China and the evolution of mainland China to a more capitalistic economy, these findings seem reasonable, even though this regional convergence clearly does not adhere to the technology-driven definition of convergence. However, we did see that the majority of the values changes over this period took place in the much larger but less economically developed mainland China, rather than in Hong Kong. We will discuss this change further in the subsequent section on business ideology and sociocultural value changes. At this point, it is interesting to note that the values in the less technologically and economically developed mainland China converged toward those of Hong Kong, the much smaller but more technologically and economically developed society of a similar cultural heritage. These findings tentatively suggest that the business ideology may be the primary influence, but that there is also a substantial interaction with sociocultural values evolving over time. In essence, these findings provide evidence of a need for further longitudinal investigations of the role played by business ideology and sociocultural influences.

\section{Business Ideology Influence}

Consistent with the perspective that business ideology is the primary driver of longitudinal values change, we found that the business ideology results mirror, and potentially drive, those of the overall values system. In particular, we learned that mainland China's values changes reflect those of Hong Kong. Such changes are most notable in Chinese views regarding the superior-subordinate relationship and the hierarchical structure within an organization (integration). Furthermore, we see an increased people-orientation (human-heartedness) in both Hong Kong and mainland China toward the U.S. In short, Hong Kong converges with the U.S. in 2001. This people-orientation is consistent with the need to fully utilize 
resources, including human resources, as the leaders in the China societies see the opportunity for a win-win situation for themselves and employees through economic growth (Chiu, 2002). These findings also suggest the need to scrutinize the traditional definition of collectivism more closely. Triandis and Gelfand (1998) discuss collectivism in terms of horizontal and vertical components. Horizontal collectivism is the more work-related concept (e.g., the well-being of co-workers is important) and vertical collectivism is the more family-related concept (e.g., family members should stick together, no matter what sacrifices are required). In practice, horizontal collectivism could include 'country' as an economic-based nationalistic orientation. Our findings for the Machiavellianism value may reflect a horizontal collectivism orientation. In those results, both mainland China and Hong Kong showed significant increases over the period of this study. Again, the perspective that there is a need to 'catch-up', and use the means necessary to do so, is consistent with current views on developing economies. Machiavelli, the ultimate pragmatist, would be likely to concur with this line of thinking and even further acknowledge that horizontal collectivists 'do not submit easily to authority' (Triandis and Gelfand, 1998). Thus, the integration finding - decreased authority in the superior-subordinate relationship - is also consistent with the Chinese becoming horizontal collectivists during the period of this study. In sum, we found economic-based, societal-level changes reflected in the values of the managers and professionals in the Chinese workforce.

Our finding regarding locus of control may be driven more by Hong Kong politics than by economic reform in China. While the locus of control scores for both mainland China and Hong Kong managers moved toward each other over this period, only the Hong Kong score change was significant. For Hong Kong, we found a more external locus of control orientation in 2001 than in 1989. Thus, while Hong Kong has viewed current political and economic ties with mainland China as crucial to their success and survival, there is also the realization that Hong Kong has relatively little control over these ties (Moon and Gage, 2003). As suggested by these data, one consequence may be that Hong Kong has accepted that economic, as well as political, control is now more in the hands of others, namely mainland China. In essence, the acceptance of external control over their fate may be a result of a degree of learned helplessness following repatriation (Petersen, Maier, and Seligman, 1995). In sum, our finding of business ideology influences at the specific values level is consistent with Rugman and Verbeke's (2004) conclusion that the great majority of multinational enterprises follow a regionalism, rather than globalization strategy.

\section{Sociocultural Influence}

While the results for the sociocultural influence are somewhat similar to the business ideology findings, there was a subtle but important distinction. For the socio- 
cultural values, we found that instead of China moving to be more similar to the values of Hong Kong, these two culturally similar societies mutually moved towards one another. Thus, they are converging but not following the technologydriven path described by traditional convergence theorists. At the specific values level, we found that the values change in both Hong Kong and China was in the direction of the other. However, Hong Kong changed significantly, and China did not for Confucian work dynamism and intolerance of ambiguity. Concomitantly, China changed significantly and Hong Kong did not for moral discipline. The changes for dogmatism were not sufficient to be significant for either. Thus, it was a crossverging process that led to this Greater China convergence in 2001.

We found that Hong Kong managers in 2001 expressed an increased desire for more certainty. At the same time, they also more strongly supported the Confucian philosophy that emphasizes social hierarchy and structure. The uncertainty of repatriation appears to be reflected in these changing Hong Kong values. Conversely, the change in mainland China indicates a strengthening adherence to collectivism, which may appear curious given mainland China's transition to capitalism and its increasing individualistic tendencies (Ralston et al., 1997). However, as Triandis (1995) has noted, individualism and collectivism are not polar points on the same continuum. Furthermore, while we cannot directly measure horizontal collectivism with the Confucian work dynamism dimension, the significant increase in mainland China over this period appears to represent the growing cooperation at work to build a more efficient and effective economy. In sum, while we found fewer changes in the sociocultural values than we did for the business ideology values, we did find some sociocultural values changed over this period, contrary to traditional thinking.

To summarize, in 1989, China had only minimally transitioned to being a market economy, while by 2001, the transition process had greatly accelerated. Likewise, in 1989, Hong Kong was still a number of years away from repatriation, with both sides presenting a positive picture of the future. By 2001, Hong Kong had experienced the reality of its new relationship with China. As such, the change in the business ideology and the resultant uncertainty brought about by these changes were greater in 2001 than they were in 1989 for both China and Hong Kong. In addition, given the unique relationship between Hong Kong and China over the period of this study, the political ramifications of Hong Kong's reunification with economically transitioning China appear to be the primary driving forces behind these values changes. Thus, we conclude that these Chinese societies, which are in the midst of radical change and uncertainty, share an increased desire for personal control and stability. We further conclude that this mutual desire is integrated with the Confucian-embraced need for persistence and an unrelenting orientation that focuses beyond immediate challenges onto the long-term goals of one's in-group. The findings of this longitudinal investigation clearly provide evidence of substantial values system evolution over a relatively 
short period of time within Greater China as both China and Hong Kong feel their way through the economic and political transitions that inextricably intertwine them.

\section{Limitations and Directions for Future Research}

This study has several limitations. First, our study is longitudinal at the societal level. While this was the goal of our study, conducting a longitudinal assessment of the values evolution at the individual level, by tracking the same subjects, would provide important information concerning the impact of societal and cultural influences on life-stage evolution across cultures (Ikels, Keith, Dickerson-Putman, Draper, Fry, Glascock, and Hanpending, 1992). Second, 12 years may or may not be sufficient time for values convergence to have taken place. Therefore, this time period may not be long enough to observe convergence across societies. Additionally, crossvergence may be a transitional period. However, the exact time for convergence to occur is a theoretical and empirical problem that awaits further research (Ralston et al., 1997). Third, given that we conducted our 2001 data collection relatively soon after the 1997 repatriation movement for Hong Kong, we must question whether the values shift that we found in Hong Kong represents a permanent or a temporary shift. Additionally, the Hong Kong business subculture will be increasingly populated by the new generation whose base values orientation may reflect the 'trauma', of repatriation. Thus, this question appears relevant for future research. In conclusion, and ideally, we would have preferred additional data-collection time points both within and beyond this 12-year period in order to identify a more specific pattern of values evolution across these societies.

\section{GONCLUSION}

The crossvergence findings of this study indicate that business ideology influences play a role in both mainland China's and Hong Kong's values evolution. Economic factors included in business ideology appear to be the driving forces in mainland China's values system evolution as China transitions to a market-based system. Political influences appear to be the primary force for change in Hong Kong as it adjusts to being a sovereign part of mainland China. However, these forces of business ideology do not result in changes toward convergence with the advanced industrial democratic societies, such as the U.S., as modernization theory would argue (Inglehart and Baker, 2000). While there were fewer changes in sociocultural values than in business ideology values, we found that some sociocultural values did change over this period, contrary to traditional convergence theory.

In summary, our findings identify both business ideology and sociocultural influences as having an impact on the values systems within any society, but especially in transitional societies, such as these two Greater China societies. Furthermore, 
the sociocultural influences do not maintain the divergent set of relationships as argued by classic divergence theory (Webber, 1969). As a result, neither convergence nor divergence theories could fully account for the pattern of societal values evolution observed. We hope this study provides insights into the area of values evolution and also raises a number of interesting questions for future research, including additional longitudinal research in a broader and more diverse range of societies.

\section{NOTES}

[1] For the 1989 data, we used that which was reported in the Ralston et al. (1993) study, for which mean and standard deviation values, but not alpha coefficients, were available. We only needed the means and standard deviation values for computing F-values, t-scores, and the cluster analysis (Glass and Hopkins, 1970).

For a 2-factor ANOVA, the sums of squares between and sum of squares cells (used to estimate interaction) are strictly a function of means and sample sizes for each cell. Thus,

$$
\begin{aligned}
& S S(A)=K \sum_{j} n_{j}\left(\bar{y}_{j .}-\bar{y}_{.}\right)^{2} \\
& S S(B)=7 \sum_{k} n_{k}\left(\bar{y}_{. k}-\bar{y}_{. .}\right)^{2} \\
& S S(A B)=\sum_{k} \sum_{j} n_{k}\left(\bar{y}_{j k}-\bar{y}_{j .}-\bar{y}_{. k}+\bar{y}_{. .}\right)^{2} .
\end{aligned}
$$

Additionally, the sum of squares within $[S S(W)]$ is strictly a function of the sample variances and sample sizes from each cell. The variances come from the standard deviations of the descriptive statistics.

$$
S S(W)=\sum_{k} \sum_{j}\left(n_{j k}-1\right) s_{j k}^{2}
$$

Finally, the mean squares and test statistics can now be calculated in the normal fashion.

In this study, each cell in the design is a country for a given year, where:

- $\mathcal{Z}$ and $K$ are the number of rows and columns respectively in the design.

- $j$ and $k$ are the counting indexes for rows and columns respectively (for the summation operation).

- $n_{j k}$ is the sample size for a particular cell. $n_{j}$ and $n_{k}$ are the samples sizes for an entire (single) row or column.

The authors thank Anne Tsui, MOR Editor-in-Chief, for her many helpful comments and suggestions in developing this article. 


\section{APPENDIX}

Table Al. Within-group inter-rater agreement $\left(\mathrm{r}_{\mathrm{WG}}\right)$ for the 8 values

\begin{tabular}{|c|c|c|c|c|c|c|}
\hline \multirow[b]{2}{*}{ Values } & \multicolumn{2}{|l|}{ U.S. } & \multicolumn{2}{|c|}{ Hong Kong } & \multicolumn{2}{|l|}{ China } \\
\hline & 1989 & 2001 & 1989 & 2001 & 1989 & 2001 \\
\hline Integration & 0.97 & 0.95 & 0.94 & 0.95 & 0.93 & 0.95 \\
\hline Human-heartedness & 0.90 & 0.88 & 0.92 & 0.94 & 0.96 & 0.94 \\
\hline Machiavellianism & 0.91 & 0.90 & 0.79 & 0.89 & 0.74 & 0.96 \\
\hline Locus of control & 0.66 & 0.71 & 0.64 & 0.64 & 0.67 & 0.75 \\
\hline Confucian dynamism & 0.95 & 0.94 & 0.95 & 0.96 & 0.95 & 0.94 \\
\hline Moral discipline & 0.90 & 0.92 & 0.88 & 0.90 & 0.86 & 0.86 \\
\hline Intolerance of ambiguity & 0.79 & 0.83 & 0.78 & 0.87 & 0.77 & 0.81 \\
\hline Dogmatism & 0.76 & 0.82 & 0.80 & 0.82 & 0.90 & 0.74 \\
\hline
\end{tabular}

\section{REFERENCES}

Adler, N. J., Campbell, N. and Laurent, A. (1989). 'In search of appropriate methodology: From outside the People's Republic of China looking in'. Fournal of International Business Studies, 20, $61-74$.

Aldenderfer, M. S. and Blashfield, R. K. (1984). Cluster Analysis. London: Sage.

Axelrod, R. (1997). 'The dissemination of culture. A model with local convergence and global polarization'. Fournal of Confict Resolution, 41, 203-26.

Bass, B. M. (1990). Bass $\mathcal{E}$ Stogdill's Handbook of Leadership: Theory, Research, and Managerial Applications (3rd edition). New York: The Free Press, (pp. 473-510).

Blau, G. J. (1987). 'Locus of control as a potential moderator of the turnover process'. Journal of Occupational Psychology, 60, 1, 21-29.

Blau, G. J. (1993). 'Testing the relationship of locus of control to different performance dimensions'. Fournal of Occupational and Organizational Psychology, 66, 2, 125-38.

Chen, A. (2002). 'The structure of Chinese industry and the impact from China's WTO entry'. Comparative Economic Studies, 44, 1, 72-98.

Chinese Culture Connection (1987). 'Chinese values and the search for culture-free dimensions of culture'. Fournal of Cross-Cultural Psychology, 18, 143-64.

Chiu, W. C. K. (2002). 'Do types of economic ownership matter in getting employees to commit? An exploratory study in the People's Republic of China'. International Journal of Human Resource Management, 13, 865-82.

Christie, R. (1968). 'Machiavellianism scale'. In Robinson, J. P. and Shaver, P. R. (Eds.), Measures of Social Psychological Attitudes, Ann Arbor, MI: Institute for Social Research, University of Michigan, (pp. 590-603).

Davies, M. F. (1998). 'Dogmatism and belief formation: Output interference in the processing of supporting and contradictory cognitions.' Journal of Personality and Social Psychology, 75, 2, 456-66.

Dollinger, M. J. (1983). 'Use of Budner's intolerance of ambiguity measure for entrepreneurial research'. Psychological Reports, 53, 1019-21.

Dunphy, D. (1987). 'Convergence/divergence: A temporal review of the Japanese enterprise and its management'. Academy of Management Review, 12, 3, 445-59.

Egri, G. P. and Ralston, D. A. (2004). 'Generation cohorts and personal values: A comparison of China and the U.S.'. Organization Science, 15, 210-20.

Fukuyama, F. (1995). Trust: The Social Virtues and the Creation of Prosperity. New York: Free Press. 
Glass, G. V. and Hopkins, K. D. (1970). Statistical Methods in Education and Psychology (2 ${ }^{\text {nd }}$ edition). Englewood Cliffs, NJ: Prentice-Hall.

Hofstede, G. (2001). Culture's Consequences: Comparing Values, Behaviours, Institutions, and Organizations across Nations $\left(2^{\text {nd }}\right.$ edition). Thousand Oaks, CA: Sage.

Holliday, I. and Wong, L. (2003). 'Social policy under one country, two systems: Institutional dynamics in China and Hong Kong since 1997'. Public Administration Review, 63, 3, 269-82.

Hong, J. (1998). The Internationalization of Television in China: The Evolution of Ideology, Society, and Media since the Reform. Westport, CT: Praeger.

Ikels, C., Keith, J., Dickerson-Putman, J., Draper, P., Fry, C., Glascock, A. and Hanpending, H. (1992). 'Perceptions of the adult life course: A cross-cultural analysis'. Ageing and Society, 12, 49-84.

Inglehart, R. (1997). Modernization and Postmodernization: Cultural, Economic, and Political Change in 43 Societies. Princeton, NJ: Princeton University Press.

Inglehart, R. and Baker, W. E. (2000). 'Modernization, cultural change, and the persistence of traditional values'. American Sociological Review, 65, 19-51.

Inkeles, A. (1997). National Character: A Psycho-social Perspective. New Brunswick: Transaction Publishers.

Jaffe, E. D., Nebenzahl, I. D. and Gotesdyner, H. (1989). 'Machiavellianism, task orientation, and team effectiveness revisited'. Psychological Reports, 64, 3, 819-24.

James, L. R., Demaree, R. G. and Wolf, G. (1993). ' $r_{\mathrm{wg}}$ : an assessment of within-group interrater agreement'. Fournal of Applied Psychology, 78, 306-9.

Jost, J. T., Glaser, J., Kruglanski, A. W. and Sulloway, F. J. (2003). 'Political conservatism as motivated social cognition'. Psychological Bulletin, 129, 3, 339-75.

Judge, T. A. and Bono, J. E. (2001). 'Relationship of core self-evaluation traits - self-esteem, generalized self-efficacy, locus of control, and emotional stability - with job satisfaction and job performance: A meta-analysis'. Journal of Applied Psychology, 86, 80-92.

Keefer, P. and Knack, S. (1997). 'Why don't poor countries catch up? A cross-national test of an institutional explanation'. Economic Inquiry, 35, 3, 590-602.

Kipnis, D., Schmidt, S. M. and Wilkinson, I. (1980). 'Intra-organizational influence tactics: Explorations in getting one's way'. Journal of Applied Psychology, 65, 440-52.

Kotter, J. P. (1985). Power and Influence. Free Press, New York.

Liao, D. and Sohmen, P. (2001). 'The development of modern entrepreneurship in China'. Stanford Journal of East Asian Affairs, 1, 27-33.

Machiavelli, N. (1513/1984). The Prince (translated by Daniel Donno). New York: Bantam Classics.

Martin, J. G. and Westie, F. R. (1959). 'The tolerant personality'. American Sociological Reviewe, 24, $521-28$.

Merchant, H. (2000). 'Configurations of international joint ventures'. Management International Review, 40, 2, 107-40.

Moon, M. J. and Gage, R. (2003). 'Hong Kong regime transformation at the crossroads: From the politics-administration and social capital perspectives'. International Journal of Public Administration, 26, 1, 79-95.

Nelson, G. and Gilbertson, D. (1991). 'Machiavellianism revisited'. Journal of Business Ethics, 10, 633-39.

Peng, M. W. and Shekshnia, S. V. (2001). 'How entrepreneurs create wealth in transitional economies'. Academy of Management Executive, 15, 1, 95-110.

Petersen, C., Maier, S. F. and Seligman, M. E. P. (1995). Learned Helplessness: A Theory for the Age of Personal Control. Oxford, UK: Oxford University Press.

Ralston, D. A., Egri, C. P., Stewart, S., Terpstra, R. H. and Yu, K. (1999). 'Doing business in the $21^{\text {st }}$ century with the new generation of Chinese manager: A study of generational shifts in work values in China'. Journal of International Business Studies, 30, 415-28.

Ralston, D. A., Gustafson, D. J., Cheung, F. and Terpstra, R. H. (1993). 'Differences in managerial values: A study of U.S., Hong Kong and PRC managers'. Fournal of International Business Studies, 24, 249-75.

Ralston, D. A., Holt, D. A., Terpstra, R. H. and Yu, K. (1997). 'The impact of national culture and economic ideology on managerial work values: A study of the United States, Russia, Japan, and China'. Fournal of International Business Studies, 28, 177-208.

Ralston, D. A., Yu, K., Wang, X., Terpstra, R. H. and He, W. (1996). 'The cosmopolitan Chinese manager: Findings of a study on managerial values across the six regions of China'. Journal of International Management, 2, 79-109. 
Ricks, D. A., Toyne, B. and Martinez, Z. (1990). 'Recent developments in international management research'. Fournal of Management, 16, 219-53.

Rokeach, M. (1973). The Nature of Human Values. New York: Free Press.

Rotter, J. B. (1966). 'Generalized expectancies for internal versus external control of reinforcement'. Psychological Monographs, No. 609.

Rugman, A. M. and Verbeke, A. (2004). 'A perspective on regional and global strategies of multinational enterprises'. Fournal of International Business Studies, 35, 3-18.

Schulze, R. H. K. (1962). 'A shortened version of the Rokeach Dogmatism Scale'. Journal of Psychological Studies, 13, 92-97.

Schwartz, S. H. (1992). 'Universals in the content and structure of values: Theoretical advances and empirical tests in 20 countries'. In Zanna, M. P. (Ed.), Advances in Experimental Social Psychology, San Diego: Academic Press, (pp. 1-65).

Shir, M. S. and Choy, B. S. T. (2005). 'The Pre- and Post-1997 well-being of Hong Kong residents'. Social Indicators Research, 71, 231-58.

Spector, P. E. (1982). 'Behavior in organizations as a function of employee's locus of control'. Psychological Bulletin, 47, 487-89.

Spector, P. E., Sanchez, J. I., Siu, O. L., Salgado, J. and Ma, J. (2004). 'Eastern versus western control beliefs at work: An investigation of secondary control, socioinstrumental control, and work locus of control in China and the US'. Applied Psychology, 53, 1, 38-50.

Suarez-Villa, L. (2000). Invention and the Rise of Technocapitalism. Lanham, Maryland: Rowman \& Littlefield.

Sun Tzu (1963). The Art of War (translated by Samuel B. Griffith). London: Oxford University Press.

Tan, B. (2002). 'The impact of national environment on managerial value systems: A comparative study of Chinese managers in the United States, Singapore and the People's Republic of China'. Management International Review, 42, 4, 473-86.

Timothy, A., Thoresen, C., Pucik, V. and Welbourne, T. (1999). 'Managerial coping with organizational change: A dispositional perspective'. Fournal of Applied Psychology, 84, 107-22.

Triandis, H. C. (1995). Individualism and Collectivism. Boulder, CO: Westview Press.

Triandis, H. C. and Gelfand, M. J. (1998). "Converging measurement of horizontal and vertical individualism and collectivism'. Fournal of Personality and Social Psychology. 74, 118-28.

Trompenaars, F. (1996). 'Resolving international conflict: Culture and business strategy'. Business Strategy Review, 7, 51-68.

Webber, R. H. (1969). 'Convergence or divergence'. Columbia Journal of World Business, 4, 3, 75-83.

Yip, G. S. (1992). Total Global Strategy: Managing for Worldwide Competitive Advantage. Englewoods Cliffs, NJ: Prentice-Hall.

David A. Ralston (dralston@ou.edu) is a Professor and the Price Chair of International Business at the University of Oklahoma. His research focuses on the cross-cultural aspects of values, influence, ethics, corporate responsibility, and stress. He has served as a guest editor for the Fournal of International Business Studies and the Academy of Management Review. He will be a guest editor for a forthcoming issue of the Journal of International

\section{Management.}

James Pounder (james.pounder@hct.ac.ae) holds doctorates in both management and education. He is currently Dean of Business at the Higher Colleges of Technology in the United Arab Emirates. His research interests include cross-cultural management, leadership, and organizational effectiveness.

Carlos Wing-Hung Lo (mscarlos@polyu.edu.hk) obtained his Ph.D. from the Flinders University of South Australia in 1990 and Doctor of Law from 
Renmin University of China in 2001. He is a Professor in the Department of Management and Marketing at the Hong Kong Polytechnic University, with research interests in the areas of Chinese law and government, environmental regulation, and corporate environmental management. His research has appeared in American Journal of Comparative Law, Journal of Public Policy, Environment and Planning A, World Development, and The China Quarterly.

Yim-Yu Wong (yywong@sfsu.edu) is a Professor of International Business at San Francisco State University. Her research covers strategic management, global strategic issues in emerging and transitional economies, international diversification, cultural values in the workplace, and knowledge transfer.

Carolyn P. Egri (egri@sfu.ca) earned her Ph.D. at the University of British Columbia. She is a Professor of Management and Organization Studies in the Faculty of Business at Simon Fraser University, as well as a Visiting Professor of Management at Xi'an Jiaotong University. Her research and teaching interests include international management, corporate environmental and social responsibility, leadership, and organization change. She is a feature editor of the Organization and Environment journal, and has served as a guest co-editor of the Leadership Quarterly, an assistant editor and guest co-editor of the Journal of Management Education, a director of the Organizational Behavior Teaching Society, and Chair of the Organizations and the Natural Environment Interest Group of the Academy of Management.

Joe Stauffer (joe_stauffer@tamu-commerce.edu) earned his Ph.D. at the University of Oklahoma. He is an Assistant Professor of Management and interim department head of Marketing and Management at Texas A\&M University - Commerce. His research interest is fairness in employment. His work has appeared in Psychometrika, Psychological Methods, Journal of Applied Psychology, and Educational and Psychological Measurement.

Manuscript received: January 11, 2005

Final version accepted: October 24, 2005

Accepted by: Anne S. Tsui 